\title{
Multi-Platform Detection of Small Ruminant Lentivirus Antibodies and Provirus as Biomarkers of Production Losses
}

\author{
Irache Echeverría ${ }^{1}$, Ricardo De Miguel ${ }^{2}$, Lorena De Pablo-Maiso ${ }^{1}$, Idoia Glaria ${ }^{1}$, \\ Alfredo A. Benito ${ }^{3}$, Ignacio De Blas ${ }^{2}$, Damián De Andrés ${ }^{1}$, Lluís Luján ${ }^{2}$ and \\ Ramsés Reina ${ }^{1 *}$ \\ ${ }^{1}$ Animal Health Department, Institute of Agrobiotechnology, CSIC-Government of Navarra, Mutilva, Spain, ${ }^{2}$ Department of \\ Animal Pathology, Instituto Universitario de Investigación Mixto Agroalimentario de Aragón (IA2), University of Zaragoza, \\ Zaragoza, Spain, ${ }^{3}$ Molecular and Cell Biology Department, EXOPOL SL, Zaragoza, Spain
}

Small ruminant lentiviruses (SRLVs) are endemic in most areas of Europe, causing a chronic infection and a multisystemic disease affecting the udder, carpal joints, lungs, and central nervous system. Due to the lack of treatments and protective vaccination strategies, infection control is focused on the identification of infected animals through serological or molecular techniques. However, antigenic and genetic heterogeneity of SRLVs represent a clear drawback for diagnosis. Infected animals may present lower animal production parameters such as birth weight or milk production and quality, depending on productive systems considered and, likely, to the diagnostic method applied. In this study, four sheep flocks dedicated to dairy or meat production were evaluated using three different ELISA and two PCR strategies to classify animal population according to SRLV infection status. Productive parameters were recorded along one whole lactation or reproductive period and compared between positive and negative animals. SRLV was present in $19 \%$ of the total population, being unequally distributed in the different flocks. Less than half of the infected animals were detected by a single diagnostic method, highlighting the importance of combining different diagnostic techniques. Statistical analysis employing animal classification using all the diagnostic methods associated lambing size, lamb weight at birth, and daily weight gain with SRLV infection status in meat flocks. Milk production, somatic cell count, fat, and protein content in the milk were associated with SRLV infection in dairy flocks, to a greater extent in the flock showing higher seroprevalence. A multi-platform SRLV diagnostic strategy was useful for ensuring correct animal classification, thus validating downstream studies investigating production traits. Keywords: small ruminant lentiviruses, diagnosis, milk production, somatic cell count, body weight, lambing size,
ELISA, PCR

\section{INTRODUCTION}

Small ruminant lentiviruses (SRLVs) cause chronic infection in sheep and goats that results in the development of a multisystemic disease that may affect animal production depending on a myriad of factors including breed susceptibility (1-3), virulence of circulating strains $(4,5)$, or production systems (6). 
Antibody production in response to infection can be detected by serological tests, while integrated provirus in circulating monocytes can be targeted by primers in PCR strategies. Despite the important contribution of ELISA approaches in control programs established so far (7), a description of novel genotypes that enlarge antigenic heterogeneity within SRLV jeopardizes ELISA performance, leading to diagnostic failures (8-11).

Quantification of productive losses due to SRLV infection remains controversial, while some studies claim for a role of SRLV infection in decreasing quantity and quality of animal productions in both dairy and meat farms (12-14), others have revealed no differences between seronegative and seropositive animals (15-19). Slow disease development is a key feature of lentiviral infections and is the main cause of the underestimated losses in terms of animal production. However, differences in the production system, breed resistance, flock management, and parameters evaluated (20) may also explain the different associations between SRLV infection and productive traits.

Furthermore, diagnostics sensitivity may have significantly influenced studies aiming at evaluating production losses derived from SRLV infection. After initial assessment of antibody production for the detection of infected animals by agar gel immunodiffusion (AGID), later studies have demonstrated that ELISA methods are more sensitive (21). Beyond this, PCR and histopathology strategies can further improve the detection of virus in seronegative animals, indicating a benefit for combining molecular, and serological strategies (22). Antigenic and genetic heterogeneity of SRLVs are on the basis of the serologic and PCR test drawbacks, respectively. Indeed, antibodies against circulating strains are better detected using homologous antigens $(8,9,23)$, and primer design is critical when developing sensitive and specific PCRs (24-26).

In this study, four sheep flocks belonging to two different production systems (dairy and meat) and breeds (Raza Navarra and Latxa Navarra) were classified as SRLV infected or uninfected using three different commercial ELISA methods, a home-made PCR kit, and a commercial PCR kit. The different commercial ELISA methods globally detected a similar number of infected animals; however, the combination of the three methods identified a significantly greater infected population in all the flocks analyzed. Furthermore, commercial PCR was more sensitive than ELISA in some cases and clearly added value to SRLV diagnosis and animal classification. Different production parameters in meat and dairy flocks were recorded during one lactation or reproductive period and, after final classification according to the different tests, were negatively (birth weight and weaning weight) or positively [somatic cell count (SCC)] associated with SRLV infection.

These results highlight the importance of using a multiplatform strategy to detect the humoral response to, as well as the presence of, different circulating strains in order to unequivocally identify infected and uninfected individuals, thereby influencing downstream studies such as production losses estimation, accreditation schemes, or control programs.

\section{MATERIALS AND METHODS}

\section{Animals and Samples}

A total of 1,497 animals belonging to four different flocks dedicated to dairy or meat production were used (Table 1). Flocks A and B (meat flocks, focused on lamb production) and Flocks C and D (dairy flocks) were located in the north of Navarra (humid climate) and bred in a semi-extensive system with periods of housing, especially during lactation. In addition, Flock D was bred in an ecological production scheme. None of the studied animals presented clinical signs of SRLV disease.

Whole blood was obtained by jugular puncture and placed in EDTA- $\mathrm{K}^{3+}$ tubes. After centrifugation, plasma samples were stored at $-20^{\circ} \mathrm{C}$ until use in ELISA. Buffy coats were washed, erythrocytes lysed, resuspended in PBS, and stored at $-20^{\circ} \mathrm{C}$ until DNA extraction.

\section{ELISA Tests}

Plasma samples were tested for the presence of SRLV antibodies with three commercial ELISA kits: ELISA\#1 uses an Eradikit ${ }^{\mathrm{TM}}$ SRLV screening test (In3Diagnostic, Torino, Italia) that includes capsid recombinant proteins from different genotypes; ELISA\#2 uses ELITEST ${ }^{\mathrm{TM}}$ MVV/CAEV (Hyphen Biomed, Neuville-surOise, France) that uses recombinant a capsid protein and synthetic peptide of the TM region; and ELISA\#3 uses INgezim Maedi screening ${ }^{\mathrm{TM}}$ (Ingenasa, Eurofins Technologies, Spain) that includes synthetic peptides from the Env protein. All tests were performed following manufacturers' instructions.

Data were analyzed by considering each ELISA individually and the combinations of diagnostic kits. "Total ELISA" results were built by summarizing all positive samples to at least one of the ELISAs tested. Diagnostic efficiency was determined for each of the ELISAs in samples analyzed by the three methods, in comparison with the Total ELISA result.

\section{DNA Extraction and PCR}

Genomic DNA was extracted from buffy coat samples with and E.Z.N.A. tissue/blood kit (OMEGA, Bio-Tek, Norcross, GA, USA). DNA was quantified (NanoDrop OneC, Thermo Scientific ${ }^{\circledR}$, Waltham, MA, USA), and real-time PCRs were performed using $250 \mathrm{ng}$ of DNA (AriaMx Real Time PCR System) using the commercial kit EXOone Maedi Visna CAEV oneMix (Exopol, Spain) following manufacturer's instructions.

A total of 341 samples randomly distributed across all the flocks were analyzed by Gag PCR using primers described elsewhere (27-30). Amplicons from 28 positive reactions were sequenced for molecular characterization purposes.

An animal was finally considered as infected when at least one commercial ELISA test or one PCR method revealed a positive result (“Total Infected").

\section{Productive Parameters}

In meat production farms, the following factors were studied during one production period: lambing size, weaning date, birth and weaning weight, and daily weight gain (DWG).

In dairy production farms, total volume of produced milk, fat, and protein content, and SCC were parameters quantified in each monthly quality control during a whole lactation. 
TABLE 1 | Flocks studied: location (map), breed, production system, and total sheep in each flock.

\begin{tabular}{|c|c|c|c|}
\hline Flock & Breed & Production system & $n$ \\
\hline A & Raza Navarra & Semi-extensive meat & 376 \\
\hline B & Raza Navarra & Semi-extensive meat & 443 \\
\hline C & Latxa Navarra & Semi-extensive dairy & 240 \\
\hline$D$ & Latxa Navarra & Semi-extensive dairy & 438 \\
\hline
\end{tabular}

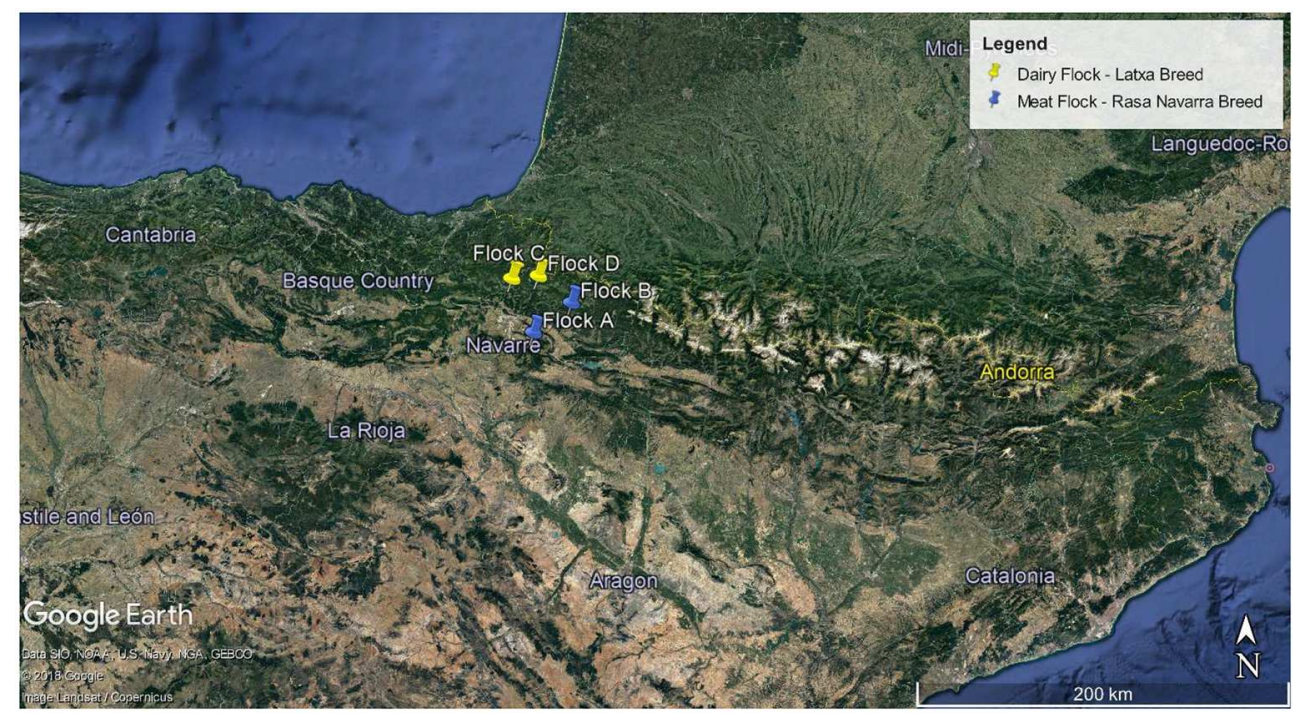

\section{Statistical Analysis}

A generalized linear model (GLM) was used to assess the effect of each diagnostic strategy on each productive parameter recorded in meat flocks, taking into account the effect of the flock and the age of the mother included as covariables. Statistical results were shown as mean and standard error (SE). Production parameters were analyzed in dairy flocks by Mann Whitney's test due to significant heterogeneity in terms of SRLV prevalence, animal management, and production values between the flocks. Medians and interquartile range (IR) are shown.

The kappa coefficient was calculated to assess the agreement between tests using the methods of Cohen-Fleiss (weighted) and Pearson-Fleiss.

Statistical analyses were carried out with IBM SPSS Statistics 19.0 for Windows, and alpha error was set at 0.050 .

\section{RESULTS}

\section{Serodiagnosis}

Serological diagnosis strongly depended on the flock and the test used. While Flocks A, B, and C presented low seroprevalence rates of up to $10 \%$, Flock $\mathrm{D}$ showed a moderate rate of seropositive animals of around $30 \%$.

Seroprevalence values in meat flocks ranged from 2.5 to $7.5 \%$ depending on the ELISA used, showing an average value of 5\% with similar ELISA efficiencies (Table 2).

However, seroprevalence in dairy flocks differed not only depending on the ELISA used but also depending on the flock.
While Flock C showed low seroprevalence values, up to $10 \%$ (range 1.9-10\%), seropositive animals in Flock D ranged from 24 to $34.1 \%$ depending on the test used. Average values considering both flocks ranged from 14.9 to $22 \%$. ELISA efficiencies differed between flocks and ELISA tests, ranging from 10 to $84 \%$ (Table 2).

Overall, ELISA\#1 showed better results in terms of reactivity, taking into account the whole population, followed by ELISA\#3 and ELISA\#2. However, when considering data within flocks, ELISA\# 1 detected a higher number of animals in Flocks A and C, whereas ELISA\#2 and ELISA\#3 were more accurate in detecting infected animals in Flocks D and B, respectively. Considering samples positive to any of the kits tested (Total ELISA), a single ELISA only detected from 19 to $57 \%$ of the seropositive animals in Flock A and from 22 to $54 \%$ in Flock B; and the range in Flock C was from 10 to $53 \%$. Single ELISA reactivity in Flock D ranged from 61 to $84.1 \%$ in comparison with Total ELISA results (Table 2).

Indeed, agreement between serological tests calculated in samples analyzed with the three methods was very good between ELISA\# 1 and ELISA\#2 only in Flock D. Values in Flocks A and $\mathrm{C}$ were not calculated since no samples were found to be simultaneously positive to more than one ELISA. In addition, association was minimal or low in Flock B (data not shown).

\section{PCR}

PCR analysis included a commercial kit that employs real-time PCR to detect and quantify different genotypes of SRLV and a 
home-made PCR based on previous publications. Commercial PCR detected more positive animals than did the classical homemade procedure, and both detected a total percentage of positive animals of $0,36.8,3.3$, and $38.5 \%$ in Flocks A, B, C, and D, respectively. These values were higher than those obtained by serological methods in all flocks, except for Flock A in which the number of samples analyzed by PCR was significantly lower. In addition, an average of $10 \%$ of the seronegative animals rendered PCR-positive reactions. Consistently, PCR and ELISA agreement was minimal (Table 3).

Sequence characterization of the Gag region in Flocks B, C, and D showed a mixed virus population between genotypes $\mathrm{A}$ and $\mathrm{B} 2$, the latter being prevalent, with high similarity in respect to previous deposited sequences. Gag immunodominant region alignment revealed no significant changes compared to sequences described (data not shown).

\section{Evaluation of Production in Meat Farms}

Lambing size, birth body weight, weaning date, and weight gain per day were affected depending on animal classification using single or combined ELISA results as well as PCRs. Lambing size was not affected when animal classification was conducted with single ELISAs; however, a combination of the three ELISAs and Total ELISA data revealed a significant positive association. A combination of PCRs also associated SRLV infection status with higher lambing size. However, a combination of serological and molecular tests associated SRLV infection with lower lambing size (Table 4).

Birth weight was also associated when animals were classified according to ELISA combinations but not when considering the Total Infected result. SRLV infection influenced weaning date when considering a combination of the serological tests or the Total Infected data. Finally, gain per day was not associated when animals were classified according to single considered methods; however, the Total Infected result showed significant association with lower DWG values (Table 4).

Total ELISA-positive animals were further classified into PCR negative or positive, and production losses were evaluated (Table 5). Lower birth weight, weaning date, weight, and DWG values were observed in double-positive animals.

\section{Evaluation of Production in Dairy Farms}

Classification of animals according to serological tests, individually, or collectively considered, revealed differences in SCCs between seropositive and seronegative animals (Table 6). Animal classification with both PCRs also identified elevated SCC in infected animals. Considering Total Infected animals (ELISA and PCR), SCCs were elevated in positive animals to an extent of $62 \%$ compared to uninfected individuals $(p<0.01)$. Milk yield was reduced by $6 \%$ in infected animals classified by single or combined ELISA results, as well as by commercial PCR $(p<0.05)$. Fat and protein contents were also related to SRLV serodiagnosis, while fat percentage was higher in milk from infected animals, protein content was reduced (Table 6).

TABLE 2 | SRLV serological analysis of sheep belonging to meat (A and B) or dairy (C and D) flocks, employing three commercial ELISAs (1, 2, and 3).

\begin{tabular}{|c|c|c|c|c|c|c|c|c|c|c|c|c|c|c|c|c|}
\hline \multirow[t]{3}{*}{ ELISA } & \multicolumn{4}{|c|}{ Flock A } & \multicolumn{4}{|c|}{ Flock B } & \multicolumn{4}{|c|}{ Flock C } & \multicolumn{4}{|c|}{ Flock D } \\
\hline & \multirow[t]{2}{*}{$n$} & \multicolumn{2}{|c|}{ Positive } & \multirow[t]{2}{*}{ Efficiency (\%) } & \multirow[t]{2}{*}{$n$} & \multicolumn{2}{|c|}{ Positive } & \multirow[t]{2}{*}{ Efficiency (\%) } & \multirow[t]{2}{*}{$n$} & \multicolumn{2}{|c|}{ Positive } & \multirow[t]{2}{*}{ Efficiency (\%) } & \multirow[t]{2}{*}{$n$} & \multicolumn{2}{|c|}{ Positive } & \multirow[t]{2}{*}{ Efficiency (\%) } \\
\hline & & $n$ & $\%$ & & & $n$ & $\%$ & & & $n$ & $\%$ & & & $n$ & $\%$ & \\
\hline 1 & 376 & 20 & 5.32 & 57.14 & 435 & 32 & 7.36 & 54.55 & 240 & 24 & 10 & 53.33 & 434 & 123 & 28.34 & 84.15 \\
\hline 2 & 238 & 6 & 2.52 & 19.05 & 257 & 10 & 3.89 & 22.73 & 155 & 3 & 1.94 & 10.00 & 249 & 85 & 34.14 & 80.49 \\
\hline 3 & 236 & 8 & 3.39 & 33.33 & 292 & 22 & 7.53 & 43.18 & 226 & 20 & 8.85 & 36.67 & 259 & 62 & 23.94 & 60.98 \\
\hline Total & 376 & 32 & 8.51 & - & 443 & 52 & 11.74 & - & 240 & 45 & 18.75 & - & 438 & 142 & 32.42 & - \\
\hline
\end{tabular}

Total ELISA represents sample reactivity to any of the ELISA used. Efficiency was calculated as the ratio between reactivity to a single ELISA and the Total ELISA result.

TABLE 3 | Total ELISA and PCR analyses of sheep belonging to meat (A and B) or dairy (C and D) flocks.

\begin{tabular}{|c|c|c|c|c|c|c|c|c|c|c|c|c|}
\hline \multirow[t]{3}{*}{ Test } & \multicolumn{3}{|c|}{ Flock A } & \multicolumn{3}{|c|}{ Flock B } & \multicolumn{3}{|c|}{ Flock C } & \multicolumn{3}{|c|}{ Flock D } \\
\hline & \multirow[t]{2}{*}{$n$} & \multicolumn{2}{|c|}{ Positive } & \multirow[t]{2}{*}{$n$} & \multicolumn{2}{|c|}{ Positive } & \multirow[t]{2}{*}{$n$} & \multicolumn{2}{|c|}{ Positive } & \multirow[t]{2}{*}{$n$} & \multicolumn{2}{|c|}{ Positive } \\
\hline & & $n$ & $\%$ & & $n$ & $\%$ & & $n$ & $\%$ & & $n$ & $\%$ \\
\hline Home-made PCR & 55 & 0 & 0 & 51 & 8 & 15.68 & 153 & 5 & 3.27 & 82 & 10 & 12.19 \\
\hline Commercial qPCR & ND & ND & ND & 86 & 29 & 33.72 & ND & ND & ND & 101 & 43 & 42.57 \\
\hline Total PCR & 55 & 0 & 0 & 87 & 32 & 36.78 & 153 & 5 & 3.27 & 122 & 47 & 38.52 \\
\hline Total ELISA & 376 & 32 & 8.51 & 443 & 52 & 11.74 & 240 & 45 & 18.75 & 438 & 142 & 32.42 \\
\hline Total Infected & 376 & 32 & 8.51 & 443 & 59 & 13.32 & 240 & 50 & 20.83 & 438 & 148 & 33.11 \\
\hline
\end{tabular}

Total ELISA represents sample reactivity to any of the ELISAs used. Total Infected was calculated with samples positive to any of the tests used. ND, not determined. 
TABLE 4 | Meat production parameters in Flocks A and B of the Raza Navarra breed according to SRLV infection status.

\begin{tabular}{|c|c|c|c|c|c|c|c|c|c|c|c|c|c|c|c|c|c|c|c|c|c|}
\hline \multicolumn{2}{|l|}{ Diagnosis } & \multicolumn{4}{|c|}{ Lambing size } & \multicolumn{4}{|c|}{ Birth weight } & \multicolumn{4}{|c|}{ Weaning date } & \multicolumn{4}{|c|}{ Weaning weight } & \multicolumn{4}{|c|}{ Daily weight gain } \\
\hline & & Mean & SE & $n$ & $p$ & Mean & SE & $n$ & $p$ & Mean & SE & $n$ & $p$ & Mean & SE & $n$ & $p$ & Mean & SE & $n$ & $p$ \\
\hline \multirow[t]{2}{*}{ ELISA\#1 } & Positive & 1.84 & 0.081 & 55 & 0.097 & 3.76 & 0.118 & 55 & 0.590 & 35.75 & 0.624 & 55 & 0.390 & 11.55 & 0.344 & 55 & 0.464 & 0.22 & 0.007 & 55 & 0.126 \\
\hline & Negative & 1.97 & 0.023 & 737 & & 3.75 & 0.029 & 730 & & 37.89 & 0.236 & 703 & & 11.85 & 0.109 & 678 & & 0.21 & 0.002 & 678 & \\
\hline \multirow[t]{2}{*}{ ELISA\#2 } & Positive & 1.89 & 0.151 & 19 & 0.586 & 3.77 & 0.212 & 19 & 0.642 & 36.58 & 1.305 & 19 & 0.793 & 11.40 & 0.712 & 19 & 0.783 & 0.21 & 0.013 & 19 & 0.860 \\
\hline & Negative & 1.97 & 0.026 & 552 & & 3.80 & 0.033 & 545 & & 38.03 & 0.282 & 524 & & 11.99 & 0.123 & 508 & & 0.21 & 0.003 & 508 & \\
\hline \multirow[t]{2}{*}{ ELISA\#3 } & Positive & 2.20 & 0.200 & 10 & 0.253 & 3.74 & 0.145 & 38 & 0.346 & 35.19 & 0.791 & 37 & 0.112 & 11.25 & 0.429 & 37 & 0.916 & 0.21 & 0.009 & 37 & 0.356 \\
\hline & Negative & 1.96 & 0.026 & 561 & & 3.77 & 0.033 & 543 & & 38.90 & 0.292 & 514 & & 12.15 & 0.127 & 503 & & 0.21 & 0.003 & 503 & \\
\hline \multirow[t]{2}{*}{ ELISA\#1 and ELISA\#2 } & Positive & 2.2 & 0.2 & 10 & 0.267 & 3.23 & 0.186 & 10 & $0.007^{*}$ & 38.2 & 1.555 & 10 & 0.182 & 10.03 & 0.579 & 10 & 0.065 & 0.18 & 0.027 & 10 & 0.089 \\
\hline & Negative & 1.97 & 0.027 & 571 & & 3.81 & 0.033 & 554 & & 37.98 & 0.279 & 533 & & 12.00 & 0.122 & 517 & & 0.21 & 0.058 & 517 & \\
\hline \multirow[t]{2}{*}{ ELISA\#1 and ELISA\#3 } & Positive & 2.11 & 0.261 & 9 & 0.207 & 3.29 & 0.308 & 9 & $0.013^{*}$ & 35.22 & 0.894 & 9 & 0.273 & 10.40 & 0.652 & 9 & 0.836 & 0.20 & 0.018 & 9 & 0.664 \\
\hline & Negative & 1.91 & 0.024 & 574 & & 3.78 & 0.032 & 572 & & 37.81 & 0.274 & 542 & & 12.12 & 0.124 & 531 & & 0.21 & 0.002 & 531 & \\
\hline \multirow[t]{2}{*}{ ELISA\#2 and ELISA\#3 } & Positive & 2.33 & 0.333 & 6 & 0.060 & 3.15 & 0.339 & 6 & $0.007^{\star}$ & 36.17 & 1.195 & 6 & 0.124 & 9.55 & 0.697 & 6 & 0.275 & 0.18 & 0.020 & 6 & 0.423 \\
\hline & Negative & 1.92 & 0.026 & 464 & & 3.83 & 0.036 & 462 & & 38.40 & 0.311 & 438 & & 12.05 & 0.136 & 429 & & 0.21 & 0.003 & 429 & \\
\hline \multirow[t]{2}{*}{ ELISA\#1, ELISA\#2, and ELISA\#3 } & Positive & 2.6 & 0.245 & 5 & $0.006^{*}$ & 2.90 & 0.281 & 5 & $0.001^{*}$ & 37.2 & 0.735 & 5 & $0.048^{*}$ & 8.92 & 0.365 & 5 & 0.124 & 0.16 & 0.011 & 5 & 0.158 \\
\hline & Negative & 1.91 & 0.026 & 466 & & 3.83 & 0.036 & 464 & & 38.38 & 0.310 & 440 & & 12.06 & 0.140 & 431 & & 0.21 & 0.003 & 431 & \\
\hline \multirow[t]{2}{*}{ Total ELISA } & Positive & 1.80 & 0.059 & 91 & $0.005^{\star}$ & 3.86 & 0.092 & 91 & 0.399 & 35.68 & 0.519 & 90 & $0.016^{*}$ & 11.67 & 0.289 & 90 & 0.339 & 0.22 & 0.006 & 90 & 0.098 \\
\hline & Negative & 1.98 & 0.024 & 700 & & 3.74 & 0.029 & 693 & & 38.01 & 0.243 & 667 & & 11.85 & 0.112 & 643 & & 0.21 & 0.002 & 642 & \\
\hline \multirow[t]{2}{*}{ PCR } & Positive & 1.67 & 0.142 & 12 & 0.265 & 4.01 & 0.244 & 12 & 0.414 & 35.08 & 1.171 & 12 & 0.964 & 12.27 & 0.605 & 12 & 0.520 & 0.24 & 0.013 & 12 & 0.368 \\
\hline & Negative & 1.80 & 0.069 & 80 & & 3.94 & 0.087 & 78 & & 39.96 & 0.759 & 75 & & 12.77 & 0.282 & 71 & & 0.22 & 0.007 & 71 & \\
\hline \multirow[t]{2}{*}{ Total PCR } & Positive & 2.09 & 0.094 & 45 & $0.027^{*}$ & 3.91 & 0.124 & 45 & 0.916 & 34.93 & 0.625 & 45 & 0.204 & 10.97 & 0.386 & 43 & 0.992 & 0.20 & 0.008 & 43 & 0.445 \\
\hline & Negative & 1.86 & 0.059 & 92 & & 3.81 & 0.085 & 90 & & 38.60 & 0.751 & 87 & & 12.06 & 0.322 & 84 & & 0.21 & 0.007 & 84 & \\
\hline \multirow[t]{2}{*}{ Total infected } & Positive & 1.78 & 0.055 & 101 & $0.001^{*}$ & 3.90 & 0.087 & 105 & 0.184 & 35.58 & 0.486 & 100 & $0.034^{*}$ & 11.75 & 0.269 & 100 & 0.084 & 0.22 & 0.005 & 100 & $0.021^{*}$ \\
\hline & Negative & 1.98 & 0.024 & 690 & & 3.73 & 0.029 & 693 & & 38.06 & 0.246 & 657 & & 11.84 & 0.113 & 632 & & 0.21 & 0.002 & 632 & \\
\hline
\end{tabular}

Mean, standard error (SE), and number of samples analyzed ( $n$ ) of each parameter are shown. The associated probability (p) with SRLV infection status obtained in the general linearized model is indicated. Animals were classified as positive or negative by considering the following: individual ELISAs, the result obtained with the different ELISAs (i.e., ELISA\#1 and ELISA\#2 are samples positive to both ELISA methods), the Total ELISA and Total PCR data (samples positive to any of the ELISA or PCR tested, respectively), and the Total Infected results (obtained combining Total ELISA and Total PCR results). ${ }^{*} p<0.05$. Bold values indicate significant differences. 
TABLE 5 | Meat production parameters in ELISA-positive animals from Flocks A and B of the Raza Navarra breed according to PCR infection status.

\begin{tabular}{|c|c|c|c|c|c|c|c|c|c|c|c|c|c|c|c|c|c|c|c|c|}
\hline \multirow[t]{2}{*}{ Total PCR } & \multicolumn{4}{|c|}{ Lambing size } & \multicolumn{4}{|c|}{ Birth weight } & \multicolumn{4}{|c|}{ Weaning date } & \multicolumn{4}{|c|}{ Weaning weight } & \multicolumn{4}{|c|}{ Daily weight gain } \\
\hline & Mean & SE & $n$ & $p$ & Mean & SE & $n$ & $p$ & Mean & SE & $n$ & $p$ & Mean & SE & $n$ & $p$ & Mean & SE & $n$ & $p$ \\
\hline Positive & 2.38 & 0.59 & 16 & $0.000^{*}$ & 3.41 & 0.85 & 16 & 0.147 & 33.94 & 8.49 & 16 & $0.026^{\star}$ & 9.34 & 2.33 & 16 & $0.001^{*}$ & 0.17 & 0.04 & 16 & $0.004^{\star}$ \\
\hline Negative & 1.75 & 0.33 & 28 & & 3.81 & 0.72 & 28 & & 37.58 & 7.37 & 26 & & 12.20 & 2.39 & 26 & & 0.22 & 0.04 & 26 & \\
\hline
\end{tabular}

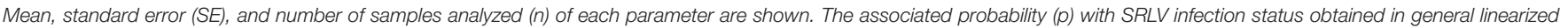
model is indicated. * $p<0.05$. Bold values indicate significant differences.

Total ELISA-positive animals were again further classified into PCR-negative or PCR-positive animals (Table 7). While milk yield and protein content were reduced in ELISA- and PCRpositive animals, milk fat was inversely affected. A tendency to higher SCC was also observed in double-positive animals.

\section{DISCUSSION}

Serological diagnosis is currently the best choice for SRLV detection in livestock. It has been widely applied in control programs but also in downstream studies evaluating production losses $(21,31)$ or genetic susceptibility and resistance to lentiviral infection (32). However, serological methods may fail at detecting the whole infected population due to virus antigenic diversity (10, 33,34 ) or to delayed seroconversion (35), encouraging the update of existing serological methods to new variants and challenging the development and evaluation of molecular methods.

In this study, we analyze an ovine population of $\sim 1,500$ individuals by ELISA methods detecting antibodies that recognize different antigen preparations. Our results demonstrate that care should be taken when ELISA tests are considered individually, since the combination of tests is able to increase the detection of seropositive animals up to $50 \%$. In addition, we included the evaluation of a recently developed commercial qPCR that showed better detection of infected animals when compared with individual ELISA results (Table 3). These results demonstrate that the truly infected population cannot be assessed by using a single ELISA strategy or even when applying three different commercial ELISA tests, since about $10 \%$ of infected animals remained seronegative but provirus positive and detected by PCR. SRLV seroprevalence in animals varied substantially when applying just one of the herein studied ELISA methods ranging from 2 to $34 \%$ of positive animals. A combination with PCR results, either commercial or home-made, enriched the infected population in different percentages depending on the flock studied, further modifying animal classification.

Three of the analyzed flocks, two of the Rasa Navarra breed (Flocks A and B) intended for meat production, and one milk flock of the Latxa Navarra breed (Flock C) presented low seroprevalence values. However, the remaining milk flock from the Latxa Navarra breed presented a moderate seroprevalence of around $30 \%$ excluding breed or production system influence.

Antigenic heterogeneity of SRLVs seems to be at the basis for this relatively low individual sensitivity. Consistently, the antigenic preparations included in the different ELISAs used may account for this different performance, since antigenic spectrum of the circulating strains in the studied population is also a key point to consider (36). Preliminary genetic characterization of the SRLVs in the different flocks reveals the presence of a mixed virus population including strains from different genotypes and subtypes. This may explain the better performance of the ELISA test including the highest antigenic diversity.

In spite of including antigenic preparations from different genotypes, ELISA failed at detecting a proportion of infected animals that were evidenced by molecular techniques. Infection by divergent SRLV strains in these animals is unlikely since primers used in PCR were designed based on known genotypes. Instead, low or fluctuating antibody titers may account for this discrepancy between serological and molecular techniques (36, 37). Indeed, absence of serological response has been described in the periparturient period (38) as well as a result of recent infections (39). Additionally, antibody response in infected animals to viral epitopes not included in ELISAs cannot be ruled out. Therefore, the previously suggested combination between ELISA and PCR to really achieve a "gold standard" $(20,21)$ is reinforced from these results.

The use of more than one diagnostic technique allowed the evaluation of different animal classifications according to single ELISA, combined Total ELISA results, and the combination of these with PCRs, resulting in a Total Infected classification. Proper classification enabled determination of the real effect SRLV infection had on production traits. Of note, the use of a single ELISA may represent the detection of roughly the $61-84 \%$ of the seropositive animals as shown in Flock D of moderate seroprevalence. Furthermore, in low-seroprevalence flocks, a single ELISA may only detect $10 \%$ of the seropositive animals. ELISA performance differed among flocks, while results from Flocks A, B and C showed low seroprevalence and ELISA efficiency; in Flock D, seroprevalence and efficiency reached 32 and $84 \%$, respectively. Breed, age, production system, nutrition, or animal management cannot be argued as important factors, since Flock C shared these features. Instead, circulation of a more prototypic SRLV in Flock D could explain this better performance.

In meat flocks, SRLV influence on animal production was clearly evidenced when serological tests were combined between them or with molecular tests. Furthermore, different interpretations could be reached, taking into account the different animal classifications. Total Infected animals, including PCR and ELISA, showed lower lambing sizes and a trend to 
TABLE 6 | Milk production parameters evaluated in Flocks $C$ and D from the Latxa breed according to SRLV infection status.

\begin{tabular}{|c|c|c|c|c|c|c|c|c|c|c|c|c|c|c|c|c|c|}
\hline \multirow[t]{2}{*}{ Diagnosis } & & \multicolumn{4}{|c|}{$\operatorname{scc}\left(\times 10^{3}\right.$ cells $\left./ \mathrm{ml}\right)$} & \multicolumn{4}{|c|}{ Milk yield } & \multicolumn{4}{|c|}{ Milk fat } & \multicolumn{4}{|c|}{ Milk protein } \\
\hline & & Median & IQR & $n$ & $p$ & Median & IQR & $n$ & $p$ & Median & IQR & $n$ & $p$ & Median & IQR & $n$ & $p$ \\
\hline \multirow[t]{2}{*}{ ELISA\#1 } & Positive & 145.25 & 446.4 & 119 & $0.004^{*}$ & 119 & 55 & 115 & $0.001^{*}$ & 6.75 & 1.31 & 119 & $0.001^{*}$ & 5.02 & 0.55 & 119 & $0.03^{*}$ \\
\hline & Negative & 106.7 & 176.29 & 417 & & 133.5 & 59.75 & 390 & & 6.50 & 1.23 & 417 & & 5.08 & 0.7 & 417 & \\
\hline \multirow[t]{2}{*}{ ELISA\#2 } & Positive & 191.6 & 624.3 & 68 & $0.001^{*}$ & 117 & 46.5 & 65 & $<0.001^{*}$ & 6.99 & 0.96 & 68 & $<0.001^{*}$ & 4.9 & 0.46 & 68 & $0.015^{\star}$ \\
\hline & Negative & 104.6 & 160.9 & 261 & & 136 & 65 & 248 & & 6.47 & 1.35 & 261 & & 5.07 & 0.62 & 261 & \\
\hline \multirow[t]{2}{*}{ ELISA\#3 } & Positive & 133.75 & 616.8 & 67 & 0.165 & 123 & 59 & 63 & $0.018^{*}$ & 6.67 & 1.12 & 67 & $0.001^{*}$ & 5.02 & 0.52 & 67 & 0.181 \\
\hline & Negative & 110.27 & 192.9 & 311 & & 140.5 & 61.25 & 297 & & 6.34 & 1.31 & 311 & & 5.17 & 0.67 & 311 & \\
\hline \multirow[t]{2}{*}{ ELISA\#1 and ELISA\#2 } & Positive & 193.75 & 631.25 & 60 & $0.001^{\star}$ & 117 & 47 & 59 & $<0.001^{*}$ & 7.05 & 098 & 60 & $<0.001^{*}$ & 4.91 & 0.45 & 60 & $0.013^{*}$ \\
\hline & Negative & 104.6 & 161.85 & 269 & & 135 & 63.5 & 254 & & 6.47 & 1.33 & 269 & & 5.06 & 0.63 & 269 & \\
\hline \multirow[t]{2}{*}{ ELISA\#1 and ELISA\#3 } & Positive & 191.6 & 695.6 & 39 & $0.048^{\star}$ & 115 & 60.5 & 39 & $<0.001^{\star}$ & 7.05 & 0.89 & 39 & $<0.001^{\star}$ & 4.93 & 0.37 & 39 & $0.008^{*}$ \\
\hline & Negative & 109.8 & 197.7 & 338 & & 140 & 62 & 320 & & 6.34 & 1.28 & 338 & & 5.19 & 0.68 & 338 & \\
\hline \multirow[t]{2}{*}{ ELISA\#2 and ELISA\#3 } & Positive & 267 & 703.5 & 35 & $0.003^{*}$ & 109.5 & 62.75 & 33 & $0.001^{*}$ & 7.06 & 0.95 & 35 & $<0.001^{*}$ & 4.88 & 0.37 & 35 & 0.115 \\
\hline & Negative & 106.51 & 161.16 & 246 & & 136.5 & 62.5 & 232 & & 6.4 & 5.94 & 246 & & 5.07 & 0.66 & 246 & \\
\hline \multirow[t]{2}{*}{ ELISA\#1, ELISA\#2, and ELISA\#3 } & Positive & 328.25 & 712.92 & 33 & $0.003^{*}$ & 115 & 65 & 32 & $0.002^{*}$ & 7.07 & 0.91 & 33 & $<0.001^{*}$ & 4.88 & 0.36 & 33 & 0.147 \\
\hline & Negative & 106.33 & 157.94 & 249 & & 136.5 & 63.5 & 234 & & 6.40 & 1.38 & 249 & & 5.06 & 0.66 & 249 & \\
\hline \multirow[t]{2}{*}{ Total ELISA } & Positive & 132.35 & 396.05 & 153 & $0.009^{*}$ & 122.5 & 55.25 & 144 & $0.021^{*}$ & 6.66 & 1.21 & 153 & $0.010^{*}$ & 5.03 & 0.59 & 153 & 0.230 \\
\hline & Negative & 106.6 & 170.2 & 383 & & 133 & 60 & 361 & & 6.52 & 1.25 & 383 & & 5.08 & 0.71 & 383 & \\
\hline \multirow[t]{2}{*}{ PCR } & Positive & 185.7 & 180.74 & 12 & 0.216 & 146 & 60.75 & 11 & 0.216 & 6.87 & 0.97 & 12 & $0.008^{*}$ & 5.25 & 1.1 & 12 & 0.954 \\
\hline & Negative & 108.75 & 273.3 & 186 & & 153 & 67 & 175 & & 6.15 & 1.39 & 186 & & 5.23 & 0.59 & 186 & \\
\hline \multirow[t]{2}{*}{ Total PCR } & Positive & 166.25 & 402.85 & 42 & $0.011^{*}$ & 120 & 48 & 40 & $<0.001^{\star}$ & 6.98 & 0.85 & 42 & $<0.001^{\star}$ & 4.95 & 0.55 & 42 & $0.011^{*}$ \\
\hline & Negative & 108.75 & 267.32 & 188 & & 155 & 69 & 178 & & 6.12 & 1.4 & 188 & & 5.23 & 0.58 & 188 & \\
\hline \multirow[t]{2}{*}{ Total infected } & Positive & 133.75 & 348 & 166 & $0.005^{\star}$ & 125 & 53 & 157 & $0.044^{*}$ & 6.67 & 1.13 & 166 & $0.004^{*}$ & 5.03 & 0.59 & 166 & 0.350 \\
\hline & Negative & 106.32 & 172.4 & 370 & & 133 & 61 & 348 & & 6.48 & 1.29 & 370 & & 5.08 & 0.7 & 370 & \\
\hline
\end{tabular}

Median, interquartile range (IQR), and number of samples analyzed (n) are indicated. Animals were classified as positive or negative by considering the following: individual ELISAs, the result obtained with the different ELISAs (i.e., ELISA\#1 and ELISA\#2 are samples positive to both ELISA methods), the Total ELISA and Total PCR data (samples positive to any of the ELISA or PCR tested, respectively), and the Total Infected results (obtained combining Total ELISA and Total PCR results). SCC: somatic cell count. Mann-Whitney's test associated probability $(p)$ is indicated. ${ }^{\star} p<0.05$. Bold values indicate significant differences. 
TABLE 7 | Milk production parameters evaluated in ELISA-positive animals from Flocks C and D from the Latxa breed according to PCR infection status.

\begin{tabular}{|c|c|c|c|c|c|c|c|c|c|c|c|c|c|c|c|c|}
\hline \multirow[t]{2}{*}{ Total PCR } & \multicolumn{4}{|c|}{$\operatorname{SCC}\left(\times 10^{3}\right.$ cells $\left./ \mathrm{ml}\right)$} & \multicolumn{4}{|c|}{ Milk yield } & \multicolumn{4}{|c|}{ Milk fat } & \multicolumn{4}{|c|}{ Milk protein } \\
\hline & Mean & SE & $n$ & $p$ & Mean & SE & $n$ & $p$ & Mean & SE & $n$ & $p$ & Mean & SE & $n$ & $p$ \\
\hline Positive & 660.19 & 156.68 & 28 & 0.084 & 109.54 & 6.00 & 26 & $0.015^{\star}$ & 6.91 & 0.15 & 28 & $0.008^{\star}$ & 4.99 & 0.07 & 28 & 0.111 \\
\hline Negative & 474.97 & 99.45 & 53 & & 138.45 & 6.95 & 49 & & 6.39 & 0.16 & 53 & & 5.07 & 0.08 & 53 & \\
\hline
\end{tabular}

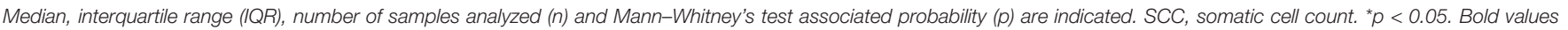
indicate significant differences.

higher birth body weight. Despite one variable possibly being related to the other, since higher lambing size implies lower birth weights (40), previous studies relate SRLV with lower birth weights (18) or rather did not find association $(16,17$, 19) likely due to the low epidemiologic importance of natural in utero transmission (41). In contrast, serological methods associated SRLV seropositivity with lower birth body weight and with lambing size depending on the data analysis performed. While positive animals to the three ELISAs used (ELISA\#1, ELISA\#2, and ELISA\#3) showed higher lambing size, ELISA combination (Total ELISA) associated lower lambing size with SRLV positivity. Since Total PCR results were in accordance with higher lambing size in positive animals, inclusion of ELISA falsepositive reactions in the Total ELISA and Total Infected groups may help to explain this discrepancy. Previous studies including one of the ELISAs used, reported specificity values ranging from 98.4 to $99.8 \%$ with respect to AGID (42), further supporting this hypothesis.

Despite the very low seroprevalence observed in meat flocks to single ELISAs, a moderate presence of infected animals ( $\sim 30 \%)$ was evidenced by PCR. Thus, PCR analysis has improved the results presented here due to detection of incipient infections that may mask SRLV influence. Chronic infections and especially SRLV show a long asymptomatic period in which ewe's body condition may inadvertently diminish, likely determining a reduced nutrient transfer to the fetus $(43,44)$. Sustained immune response in these infections may also alter the metabolism to a more catabolic profile, thereby reducing disposable input for the lamb. Actually, HIV infection has severe impact on pregnancy outcomes such as low birth weight and preterm delivery (45-47).

In dairy flocks, the application of single ELISA already identified higher SCC and fat content as well as lower milk yield and protein in milk from SRLV-seropositive sheep. A combination of ELISAs and PCR further confirmed this finding. Total Infected animals showed lower milk production (up to $3 \%$ ) and elevated SCCs (60\% increment). Augmented SCC has been already linked to SRLV infection due to epithelial cell desquamation derived from microscopic alterations in the mammary gland $(48,49)$ and may represent lower milk quality and, beyond, economic losses to farmers due to penalties. In the absence of clinical signs, increased SCC could be related to systemic incipient lesions that may be present in up to $20 \%$ of infected animals (50). Interestingly, recent studies show that up to $90.9 \%$ of naturally SRLV-infected animals exhibit minimal to moderate lesions in the mammary gland, this prevalence being even higher in intensive milk-producing systems (22). Increased fat content in the milk could be the simple consequence of lower production (51). Decreased protein content was found in infected animals, further pointing out SRLV influence on milk production parameters.

Among ELISA-positive animals, the PCR-negative population showed lower production losses as compared to PCR-positive animals in meat and dairy flocks. Higher viral load implies higher PCR sensitivity as well as increased disease severity (52-54). These results suggest that antibodies revealed in ELISA may play a protective role, thereby reducing clinical signs and production losses. In agreement, the presence of antibodies against SRLV in milk may reduce proviral load detection in milk cells (55).

Interestingly, lower weight at weaning presented by lambs from seropositive ewes in meat farms could be explained by the lower milk production observed in infected sheep from dairy flocks. However, milk production parameters were not evaluated in meat flocks.

Exhaustive estimation of production losses derived from infections, especially those chronic, should be evaluated after proper infection status evaluation. The multi-platform strategy applied here to classify more than 1,000 animals into SRLV infected vs. uninfected enabled the analysis of different production parameters in meat and milk-oriented semiextensive production systems. Proper diagnosis was achieved when three different ELISA methods and two different PCRs were used. Both meat and dairy flocks showed diminished production parameters in infected animals, mainly affecting birth and weaning weights as well as milk production together with an increased number of somatic cells counts. These results highlight the crucial importance of proper SRLV infection status determination in sheep production studies and help to clarify previous colliding results obtained by other authors.

\section{DATA AVAILABILITY STATEMENT}

All datasets generated for this study are included in the article/supplementary material.

\section{ETHICS STATEMENT}

Ethical review and approval was not required for the animal study because Samples were obtained for institutional control campaings and later used in this study. Written informed consent was obtained from the owners for the participation of their animals in this study. 


\section{AUTHOR CONTRIBUTIONS}

IE, RR, and LD were involved in processing of the samples and DNA extraction. IE, RD, and LD performed ELISA and PCR. AB, IE, and RD contributed to real-time PCR analysis. IE, RD, and ID performed statistical analysis of data. IE, RD, and RR drafted the manuscript. ID, DD, LL, IG, and RR revised the manuscript and wrote the final version. DD, LL, and RR obtained funds and coordinated and supervised the study. All co-authors approved the final version of the manuscript.

\section{FUNDING}

This research was funded by the Spanish Ministry of Science, Innovation and Universities, grant number RTI2018-096172-BC31, and by the Government of Navarra and European Union ERDF program, grant number PDR (210160006). LD and IE were

\section{REFERENCES}

1. Dawson M. Pathogenesis of maedi-visna. Vet Rec. (1987) 120:4514. doi: 10.1136/vr.120.19.451

2. Houwers DJ, Visscher AH, Defize PR. Importance of ewe/lamb relationship and breed in the epidemiology of maedi-visna virus infections. Res Vet Sci. (1989) 46:5-8. doi: 10.1016/S0034-5288(18)31108-1

3. Cutlip RC, Lehmkuhl HD, Brogden KA, Sacks JM. Breed susceptibility to ovine progressive pneumonia (maedi/visna) virus. Vet Microbiol. (1986) 12:283-8. doi: 10.1016/0378-1135(86)90057-X

4. Thormar H. The origin of lentivirus research: maedi-visna virus. Curr HIV Res. (2013) 11:2-9. doi: 10.2174/157016213804999212

5. Benavides J, Fuertes M, García-Pariente C, Otaola J, Delgado L, Giraldez J, et al. Impact of maedi-visna in intensively managed dairy sheep. Vet J. (2013) 197:607-12. doi: 10.1016/j.tvjl.2013.03.031

6. Leginagoikoa I, Juste RA, Barandika J, Amorena B, De Andrés D, Luján L, et al. Extensive rearing hinders Maedi-Visna Virus (MVV) infection in sheep. Vet Res. (2006) 37:767-78. doi: 10.1051/vetres:2006034

7. Pérez M, Biescas E, de Andrés X, Leginagoikoa I, Salazar E, Berriatua E, et al. Visna/maedi virus serology in sheep: Survey, risk factors and implementation of a successful control programme in Aragón (Spain). Vet J. (2010) 186:2215. doi: 10.1016/j.tvjl.2009.07.031

8. Olech M, Valas S, Kuzmak J. Epidemiological survey in singlespecies flocks from Poland reveals expanded genetic and antigenic diversity of small ruminant lentiviruses. PLoS ONE. (2018) 13:e0193892. doi: 10.1371/journal.pone.0193892

9. Reina R, Grego E, Profiti M, Glaria I, Robino P, Quasso A, et al. Development of specific diagnostic test for small ruminant lentivirus genotype E. Vet Microbiol. (2009) 138:251-7. doi: 10.1016/j.vetmic.2009. 04.005

10. Cardinaux L, Zahno ML, Deubelbeiss M, Zanoni R, Vogt HR, Bertoni G. Virological and phylogenetic characterization of attenuated small ruminant lentivirus isolates eluding efficient serological detection. Vet Microbiol. (2013) 162:572-81. doi: 10.1016/j.vetmic.2012.11.017

11. Olech M, Rachid A, Croisé B, Kuzmak J, Valas S. Genetic and antigenic characterization of small ruminant lentiviruses circulating in Poland. Virus Res. (2012) 163:528-36. doi: 10.1016/j.virusres.2011.11.019

12. Barquero N, Gomez-Lucia E, Arjona A, Toural C, Las Heras A, FernándezGarayzábal JF, et al. Investigation of risk factors associated with infections caused by small ruminant lentiviruses. Bull Vet Inst Pulawy. (2013) 57:4738. doi: 10.2478/bvip-2013-0082

13. Martínez-Navalón B, Peris C, Gómez EA, Peris B, Roche ML, Caballero C, et al. Quantitative estimation of the impact of caprine arthritis encephalitis virus infection on milk production by dairy goats. Vet J. (2013) 197:3117. doi: $10.1016 /$ j.tvjl.2012.12.020 funded by Universidad Pública de Navarra. RR was supported by the Spanish Ministry of Science and Innovation Ramón y Cajal contract. Authors acknowledge APC funding by the CSIC Open Access Publication Support Initiative through its Unit of Information Resources for Research (URICI). RD was a Ph.D. student funded by the Department of Innovation, Research and University of Aragón.

\section{ACKNOWLEDGMENTS}

Authors acknowledge INTIA of Navarra for blood samples and breeders association of the Raza Navarra breed (ARANA) and breeders association of the Latxa Navarra breed (ASLANA) for production data. Ana Mariela Dodero (INTA, Salta, Argentina) is acknowledged for technical assistance in obtaining buffy coat. Authors acknowledge the reviewers for their contributions as their comments have considerably improved the manuscript.

14. Dohoo IR, Heaney DP, Stevenson RG, Samagh BS, Rhodes CS. The effects of maedi-visna virus infection on productivity in ewes. Prev Vet Med. (1987) 4:471-84. doi: 10.1016/0167-5877(87)90032-8

15. Dungu B, Vorster J, Bath GF, Verwoerd DW. The effect of a natural maedi-visna virus infection on the productivity of South African sheep. Onderstepoort J Vet Res. (2000) 67:87-96.

16. Nalbert T, Czopowicz M, Szaluś-Jordanow O, Witkowski M, Witkowski L, Słoniewska D, et al. Impact of the subclinical small ruminant lentivirus infection of female goats on the litter size and the birth body weight of kids. Prev Vet Med. (2019) 165:71-5. doi: 10.1016/j.prevetmed.2019.02.011

17. Arsenault J, Dubreuil P, Girard C, Simard C, Bélanger D. Maedi-visna impact on productivity in Quebec sheep flocks (Canada). Prev Vet Med. (2003) 59:125-37. doi: 10.1016/S0167-5877(03)00086-2

18. Greenwood PL. Effects of caprine arthritis-encephalitis virus on productivity and health of dairy goats in New South Wales, Australia. Prev Vet Med. (1995) 22:71-87. doi: 10.1016/0167-5877(94)00399-4

19. Snowder GD, Gates NL, Glimp HA, Gorham JR. Prevalence and effect of subclinical ovine progressive pneumonia virus infection on ewe wool and lamb production. J Am Vet Med Assoc. (1990) 197:475-9.

20. Minguijón E, Reina R, Pérez M, Polledo L, Villoria M, Ramírez H, et al. Small ruminant lentivirus infections and diseases. Vet Microbiol. (2015) 181:7589. doi: 10.1016/j.vetmic.2015.08.007

21. de Andrés D, Klein D, Watt NJ, Berriatua E, Torsteinsdottir S, Blacklaws BA, et al. Diagnostic tests for small ruminant lentiviruses. Vet Microbiol. (2005) 107:49-62. doi: 10.1016/j.vetmic.2005.01.012

22. Gayo E, Polledo L, Magalde A, Balseiro A, García Iglesias MJ, Pérez Martínez $\mathrm{C}$, et al. Characterization of minimal lesions related to the presence of visna/maedi virus in the mammary gland and milk of dairy sheep. BMC Vet Res. (2019) 15:109. doi: 10.1186/s12917-019-1855-3

23. Lacerenza D, Giammarioli M, Grego E, Marini C, Profiti M, Rutili D, et al. Antibody response in sheep experimentally infected with different small ruminant lentivirus genotypes. Vet Immunol Immunopathol. (2006) 112:26471. doi: 10.1016/j.vetimm.2006.03.016

24. Kuhar U, Barlič-Maganja D, Grom J. Development and validation of TaqMan probe based real time PCR assays for the specific detection of genotype A and B small ruminant lentivirus strains. BMC Vet Res. (2013) 9:172. doi: 10.1186/1746-6148-9-172

25. Brinkhof JMA, van Maanen C, Wigger R, Peterson K, Houwers DJ. Specific detection of small ruminant lentiviral nucleic acid sequences located in the proviral long terminal repeat and leader-gag regions using real-time polymerase chain reaction. J Virol Methods. (2008) 147:33844. doi: 10.1016/j.jviromet.2007.10.013

26. Brajon G. Development and field testing of a real-time PCR assay for Caprine Arthritis-Encephalitis-Virus (CAEV). Open Virol J. (2012) 6:8290. doi: 10.2174/1874357901206010082 
27. Reina R, Mora MI, Glaria I, García I, Solano C, Luján L, et al. Molecular characterization and phylogenetic study of maedi visna and Caprine Arthritis Encephalitis viral sequences in sheep and goats from Spain. Virus Res. (2006) 121:189-98. doi: 10.1016/j.virusres.2006.05.011

28. Zanoni RG, Nauta IM, Kuhnert P, Pauli U, Pohl B, Peterhans E. Genomic heterogeneity of small ruminant lentiviruses detected by PCR. Vet Microbiol. (1992) 33:341-51. doi: 10.1016/0378-1135(92)90061-W

29. Grego E, Profiti M, Giammarioli M, Giannino L, Rutili D, Woodall $\mathrm{C}$, et al. Genetic heterogeneity of small ruminant lentiviruses involves immunodominant epitope of capsid antigen and affects sensitivity of single-strain-based immunoassay. Clin Diagn Lab Immunol. (2002) 9:82832. doi: 10.1128/CDLI.9.4.828-832.2002

30. Rimstad E, East NE, Torten M, Higgins J, deRock E, Pedersen NC. Delayed seroconversion following naturally acquired caprine arthritis-encephalitis virus infection in goats. Am J Vet Res. (1993) 54:1858-62.

31. Gjerset B, Rimstad E, Teige J, Soetaert K, Jonassen CM. Impact of natural sheep-goat transmission on detection and control of small ruminant lentivirus group C infections. Vet Microbiol. (2009) 135:2318. doi: 10.1016/j.vetmic.2008.09.069

32. Alshanbari FA, Mousel MR, Reynolds JO, Herrmann-Hoesing LM, Highland MA, Lewis GS, et al. Mutations in Ovis aries TMEM154 are associated with lower small ruminant lentivirus proviral concentration in one sheep flock. Anim Genet. (2014) 45:565-71. doi: 10.1111/age.12181

33. Barquero N, Domenech A, Arjona A, Fernández-Garayzabal JF, Ruiz-SantaQuiteria JA, Gomez-Lucia E. Comparison of two PCR and one ELISA techniques for the detection of small ruminant lentiviruses (SRLVs) in milk of sheep and goats. Res Vet Sci. (2013) 94:817-9. doi: 10.1016/j.rvsc.2013.01.004

34. Herrmann-Hoesing LM. Diagnostic assays used to control small ruminant lentiviruses. J Vet Diagn Invest. (2010) 22:84355. doi: 10.1177/104063871002200602

35. Kaba J, Czopowicz M, Ganter M, Nowicki M, Witkowski L, Nowicka D, et al. Risk factors associated with seropositivity to small ruminant lentiviruses in goat herds. Res Vet Sci. (2013) 94:225-7. doi: 10.1016/j.rvsc.2012.09.018

36. Sanjosé L, Pinczowski P, Crespo H, Pérez M, Glaria I, Gimeno M, et al. Diagnosing infection with small ruminant lentiviruses of genotypes A and B by combining synthetic peptides in ELISA. Vet J. (2015) 204:8893. doi: 10.1016/j.tvjl.2015.01.012

37. Nogarol C, Bertolotti L, Klevar S, Profiti M, Gjerset B, Rosati S. Serological characterization of small ruminant lentiviruses: a complete tool for serotyping lentivirus infection in goat. Small Rumin Res. (2019) 176:426. doi: 10.1016/j.smallrumres.2019.05.010

38. Czopowicz M, Szaluś-Jordanow O, Mickiewicz M, Witkowski L, Moroz A, Markowska-Daniel I, et al. Fall in antibody titer to small ruminant lentivirus in the periparturient period in goats. Small Rumin Res. (2017) 147:3740. doi: 10.1016/j.smallrumres.2016.12.006

39. Czopowicz M, Szaluś-Jordanow O, Mickiewicz M, Moroz A, Witkowski $\mathrm{L}$, Markowska-Daniel I, et al. Influence of true within-herd prevalence of small ruminant lentivirus infection in goats on agreement between serological immunoenzymatic tests. Prev Vet Med. (2017) 144:75-80. doi: 10.1016/j.prevetmed.2017.05.017

40. Gama LT, Dickerson GE, Young LD, Leymaster KA. Effects of breed, heterosis, age of dam, litter size, and birth weight on lamb mortality1. J Anim Sci. (1991) 69:2727-43. doi: 10.2527/1991.6972727x

41. Blacklaws B., Berriatua E, Torsteinsdottir S, Watt N., de Andres D, Klein D, et al. Transmission of small ruminant lentiviruses. Vet Microbiol. (2004) 101:199-208. doi: 10.1016/j.vetmic.2004.04.006

42. Saman E, van Eynde G, Lujan L, Extramiana B, Harkiss G, Tolari F, et al. A new sensitive serological assay for detection of lentivirus infections in small ruminants. Clin Diagn Lab Immunol. (1999) 6:73440. doi: 10.1128/CDLI.6.5.734-740.1999

43. Vatankhah M, Talebi MA, Zamani F. Relationship between ewe body condition score (BCS) at mating and reproductive and productive traits in Lori-Bakhtiari sheep. Small Rumin Res. (2012) 106:105-9. doi: 10.1016/j.smallrumres.2012.02.004

44. Kenyon P, Maloney S, Blache D. Review of sheep body condition score in relation to production characteristics. New Zeal J Agric Res. (2014) 57:3864. doi: 10.1080/00288233.2013.857698

45. Brocklehurst $\mathrm{P}$, French R. The association between maternal HIV infection and perinatal outcome: a systematic review of the literature and meta-analysis. BJOG An Int J Obstet Gynaecol. (1998) 105:836-48. doi: 10.1111/j.1471-0528.1998.tb10227.x

46. Xiao PL, Zhou YB, Chen Y, Yang MX, Song XX, Shi Y, et al. Association between maternal HIV infection and low birth weight and prematurity: a meta-analysis of cohort studies. BMC Pregnancy Childbirth. (2015) 15:246. doi: 10.1186/s12884-015-0684-Z

47. Cotton MF, Holgate S, Nelson A, Rabie H, Wedderburn C, Mirochnick M. The last and first frontier - Emerging challenges for HIV treatment and prevention in the first week of life with emphasis on premature and low birth weight infants. J Int AIDS Soc. (2015) 18(7Suppl. 6):20271. doi: 10.7448/IAS.18.7.20271

48. Christodoulopoulos G. Maedi-Visna: clinical review and short reference on the disease status in Mediterranean countries. Small Rumin Res. 62:4753. doi: 10.1016/j.smallrumres.2005.07.046

49. Lerondelle C, Richard Y, Issartial J. Factors affecting somatic cell counts in goat milk. Small Rumin Res. (1992) 8:129-39. doi: 10.1016/0921-4488(92)90014-U

50. Gayo E, Polledo L, Balseiro A, Martínez CP, García Iglesias MJ, Preziuso S, et al. Inflammatory lesion patterns in target organs of Visna/Maedi in sheep and their significance in the pathogenesis and diagnosis of the infection. $J$ Comp Pathol. (2018) 159:49-56. doi: 10.1016/j.jcpa.2018.01.001

51. Junkuszew A, Kuzmak J, Olech M. Milk Yield and Quality in Sheep with Maedi-Visna Virus. (2010). Available online at: https://www.researchgate.net/ publication/285762408 (accessed December 22, 2019)

52. Ravazzolo AP, Nenci C, Vogt HR, Waldvogel A, Obexer-Ruff G, Peterhans E, et al. Viral load, organ distribution, histopathological lesions, and cytokine mRNA expression in goats infected with a molecular clone of the caprine arthritis encephalitis virus. Virology. (2006) 350:11627. doi: 10.1016/j.virol.2006.02.014

53. Zhang Z, Watt NJ, Hopkins J, Harkiss G, Woodall CJ. Quantitative analysis of maedi-visna virus DNA load in peripheral blood monocytes and alveolar macrophages. J Virol Methods. (2000) 86:13-20. doi: 10.1016/S0166-0934(99)00169-X

54. Crespo H, Bertolotti L, Proffiti M, Cascio P, Cerruti F, Acutis PL, et al. Low proviral small ruminant lentivirus load as biomarker of natural restriction in goats. Vet Microbiol. (2016) 192:152-62. doi: 10.1016/j.vetmic.2016. 07.008

55. Barquero N, Gomez-Lucia E, Arjona A, Toural C, Heras A, FernándezGarayzabal J, et al. Evolution of specific antibodies and proviral DNA in milk of small ruminants infected by small ruminant lentivirus. Viruses. (2013) 5:2614-23. doi: 10.3390/v5102614

Conflict of Interest: $\mathrm{AB}$ is Head of Molecular and Cell Biology Department in Exopol.

The remaining authors declare that the research was conducted in the absence of any commercial or financial relationships that could be construed as a potential conflict of interest.

Copyright (c) 2020 Echeverría, De Miguel, De Pablo-Maiso, Glaria, Benito, De Blas, De Andrés, Luján and Reina. This is an open-access article distributed under the terms of the Creative Commons Attribution License (CC BY). The use, distribution or reproduction in other forums is permitted, provided the original author(s) and the copyright owner(s) are credited and that the original publication in this journal is cited, in accordance with accepted academic practice. No use, distribution or reproduction is permitted which does not comply with these terms. 